\title{
Compact and Transportable Iodine Frequency-Stabilized Laser
}

J. Barbarat, J. Gillot, C. Philippe, H. Alvarez-Martinez, M. Lours

D. Holleville, R. Le Targat, P-E. Pottie, P. Wolf, P. Tuckey, O. Acef

SYRTE / CNRS / Observatoire de Paris, 61, av. de l'Observatoire F-75014 Paris, France

F-X. Esnault, T. Leveque

CNES, 18, av. Edouard Belin F-31401, Toulouse, France
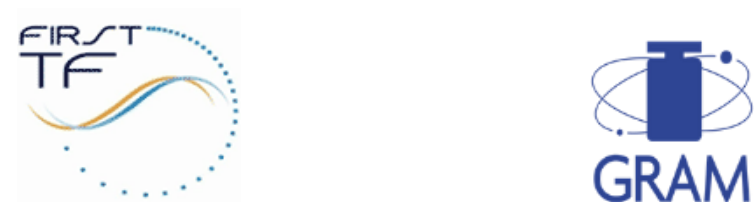
$>$ Iodine stabilized Telecom lasers

$>$ Third Harmonic Generation (THG) process

$>$ Two approaches for Doppler free iodine spectroscopy:

Modulation transfer spectroscopy (MTS)

Frequency modulation spectroscopy (FMS)

$>$ Results

$>$ Conclusion

$>$ Future developments 


\section{Telecom lasers $(\sim 1.54 \mu \mathrm{m}) \&$ Iodine lines in the green $(\sim 514 \mathrm{~nm})$}

$\square$ Telecom lasers have very low intrinsic phase noise (linewidth $\sim \mathrm{kHz}$ )

Optical amplifiers (EDFA) are powerful, compact and fibered

प Many optical devices exhibit high TRL (AOM, EOM, non linear crystals, ...)
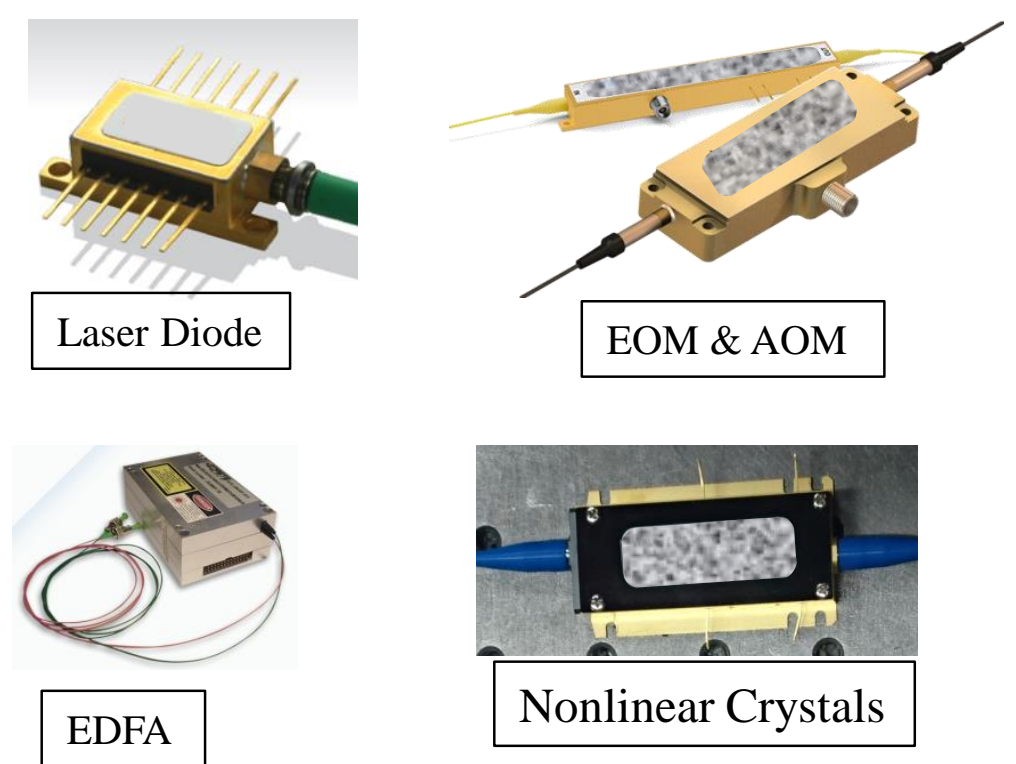


\section{Telecom lasers $(\sim 1.54 \mu \mathrm{m}) \&$ Iodine lines in the green $(\sim 514 \mathrm{~nm})$}

$\square$ Telecom lasers have very low intrinsic phase noise (linewidth $\sim \mathrm{kHz}$ )

$\square$ Optical amplifiers (EDFA) are powerful, compact and fibered

$\square$ Many optical devices exhibit high TRL (AOM, EOM, non linear crystals, ...)
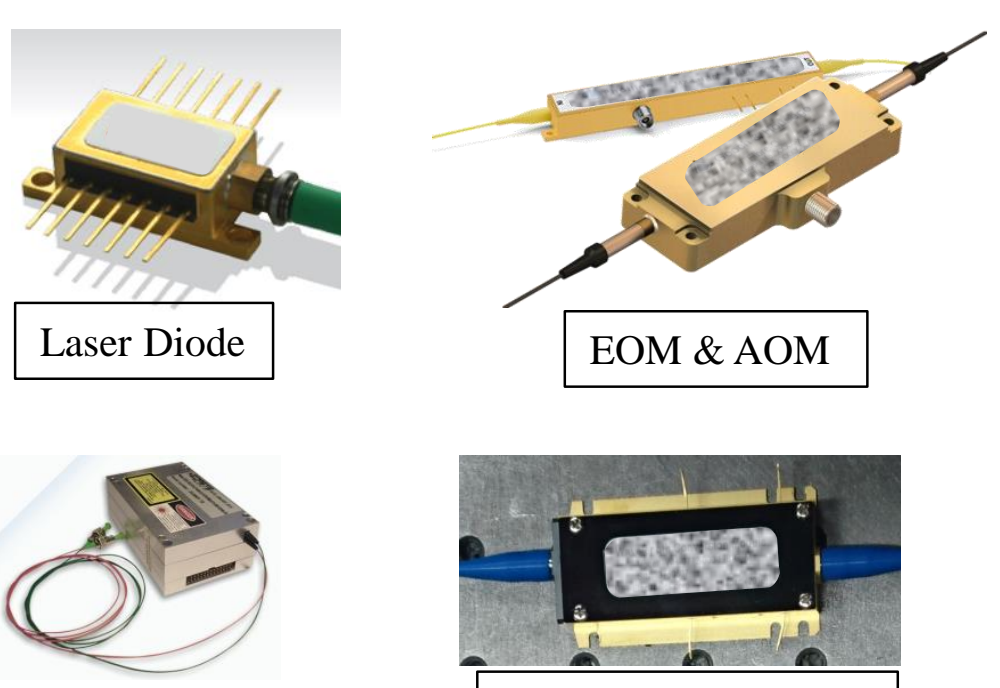

EDFA

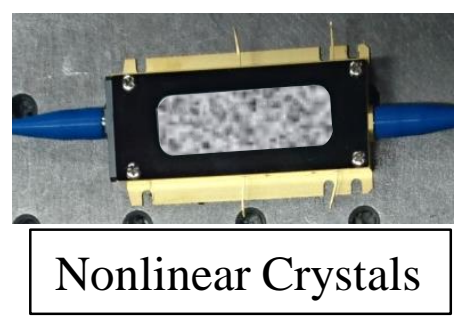

Frequency stabilities using various atomic vapors :

Direct absorption of infrared light (@ $\omega$ ): $\mathrm{C}_{2} \mathrm{H}_{2}, \mathrm{CO}$, etc .. Frequency stabilities in the range of $10^{-12}-10^{-13}$

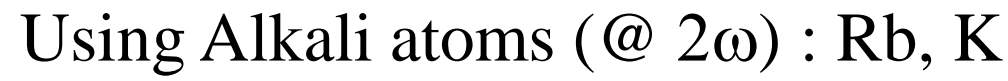

Frequency stabilities in the range of $10^{-13}-10^{-14}$

With Iodine: ${ }^{127} \mathrm{I}_{2}(@ 3 \omega)$

Frequency stabilities in the range of $10^{-14}-10^{-15}$ 


\section{Telecom lasers $(\sim 1.54 \mu \mathrm{m}) \&$ Iodine lines in the green $(\sim 514 \mathrm{~nm})$}

$\square$ Telecom lasers have very low intrinsic phase noise (linewidth $\sim \mathrm{kHz}$ )

$\square$ Optical amplifiers (EDFA) are powerful, compact and fibered

$\square$ Many optical devices exhibit high TRL (AOM, EOM, non linear crystals, ...)

Iodine hyperfine lines in the green range $(\sim 514 \mathrm{~nm})$ :

* Are narrow $\left(\mathrm{Q}>10^{9}\right)$

* Exhibit high $\mathrm{S} / \mathrm{N}$ ratio $\left(\sim 10^{5}\right.$ in $1 \mathrm{~Hz}$ bandwidth $)$

* Thousands of lines existing in the $510 \mathrm{~nm}-533 \mathrm{~nm}$ range

* Natural linewidths decrease for short wavelengths
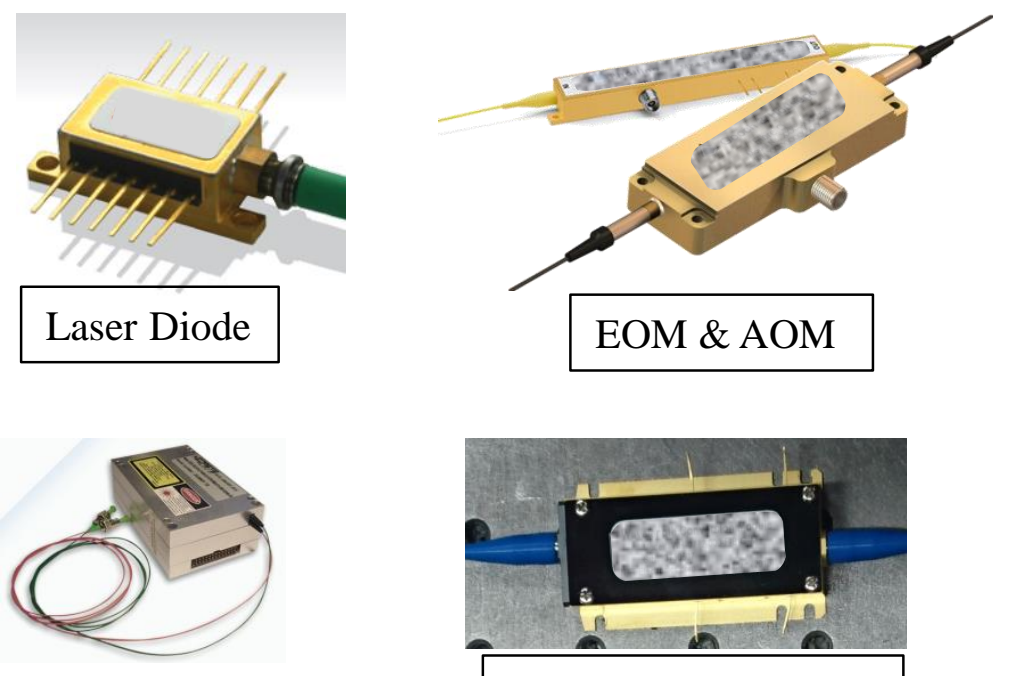

EDFA

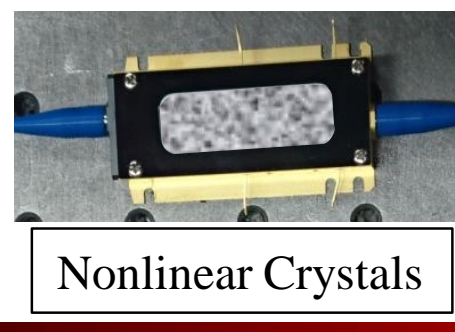

Our development

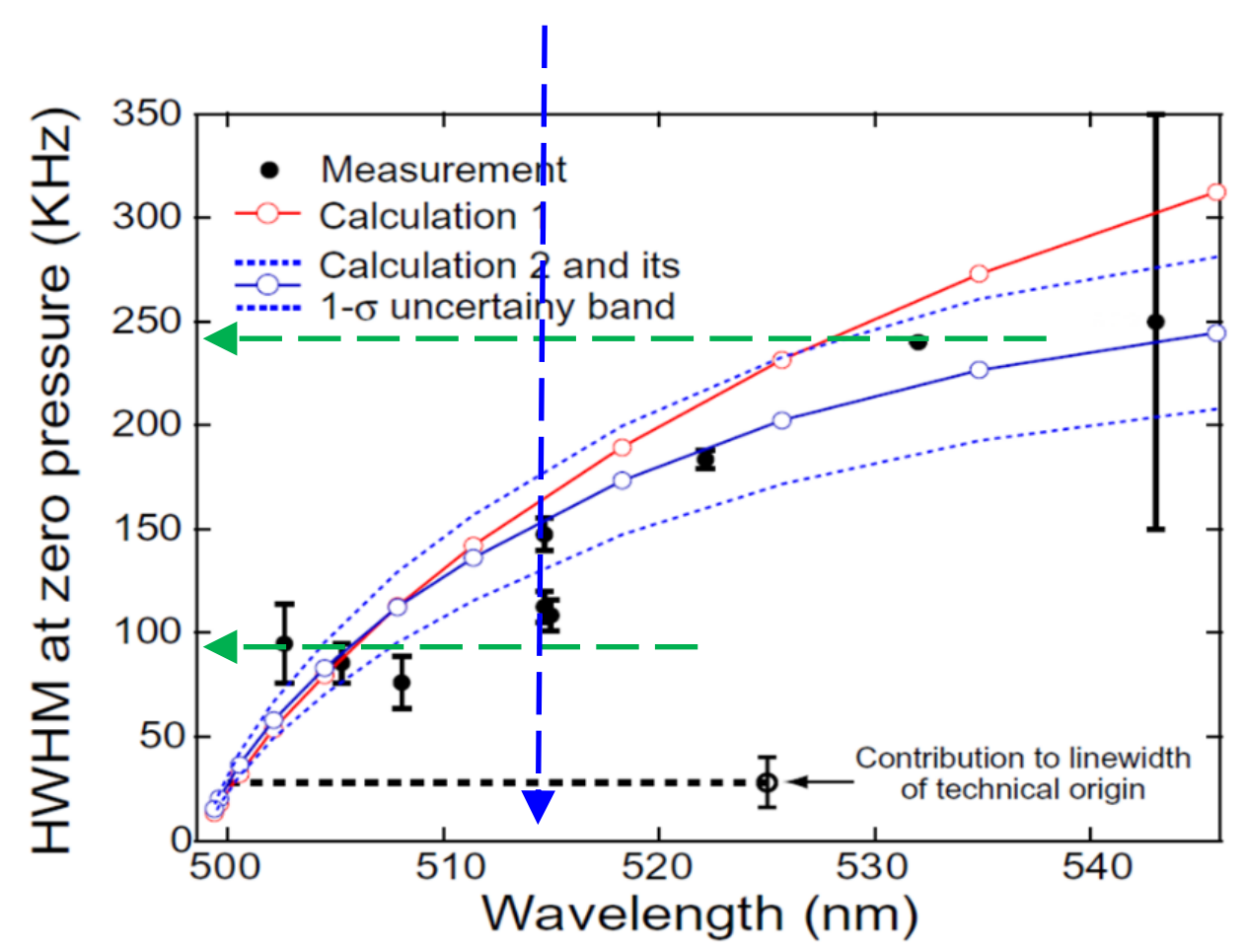

L. CHEN, «High-Precision Spectroscopy of Molecular Iodine" Thesis University of Colorado 2005 


\section{Telecom lasers $(\sim 1.54 \mu \mathrm{m}) \&$ Iodine lines in the green $(\sim 514 \mathrm{~nm})$}

$\square$ Telecom lasers have very low intrinsic phase noise (linewidth $\sim \mathrm{kHz}$ )

$\square$ Optical amplifiers (EDFA) are powerful, compact and fibered

$\square$ Many optical devices exhibit high TRL (AOM, EOM, non linear crystals, ...)

Iodine hyperfine lines in the green range $(\sim 514 \mathrm{~nm})$ :

* Are narrow $\left(\mathrm{Q}>10^{9}\right)$

* Exhibit high $\mathrm{S} / \mathrm{N}$ ratio $\left(\sim 10^{5}\right.$ in $1 \mathrm{~Hz}$ bandwidth $)$

* Thousands of lines existing in the $510 \mathrm{~nm}-533 \mathrm{~nm}$ range

* Natural linewidths decrease for short wavelengths
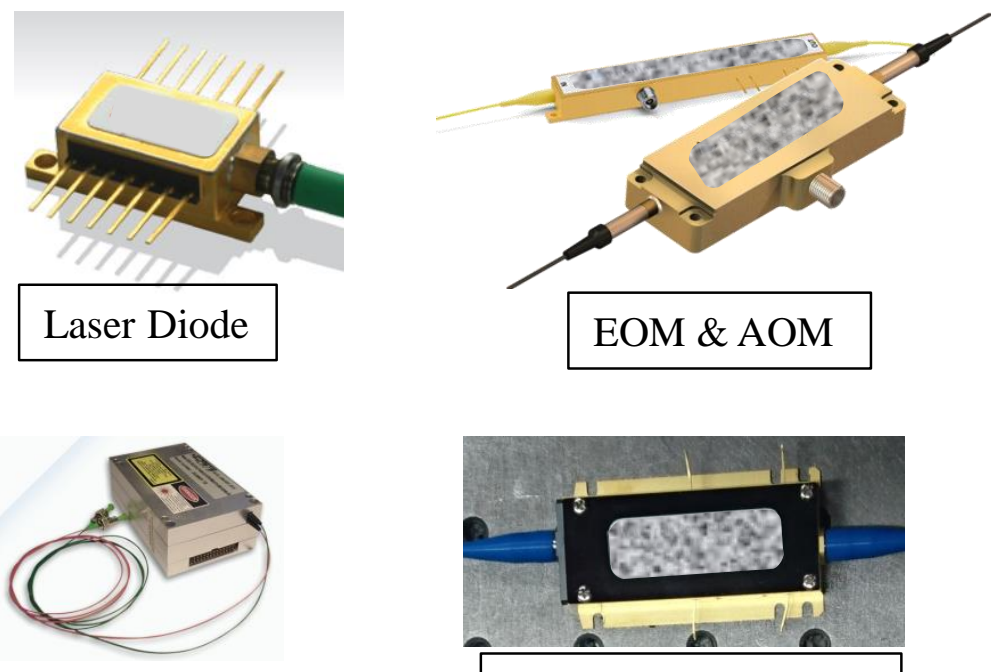

EDFA

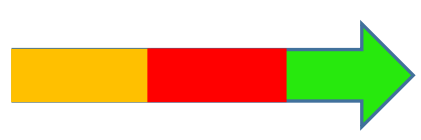

Frequency tripling process is required
Our development

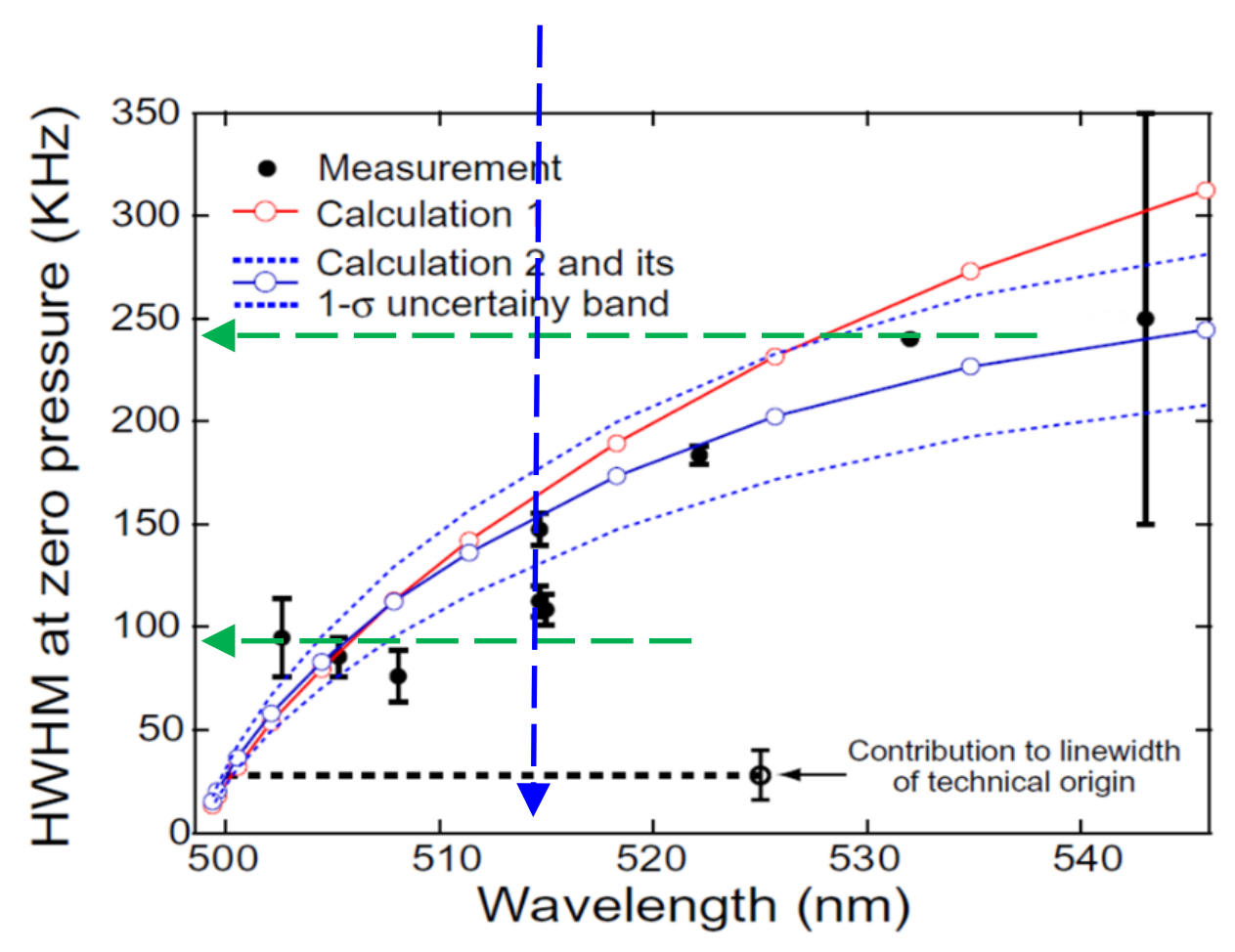

L. CHEN, «High-Precision Spectroscopy of Molecular Iodine” Thesis University of Colorado 2005 


\section{Frequency Tripling Process: Two distinct setups have been developed}

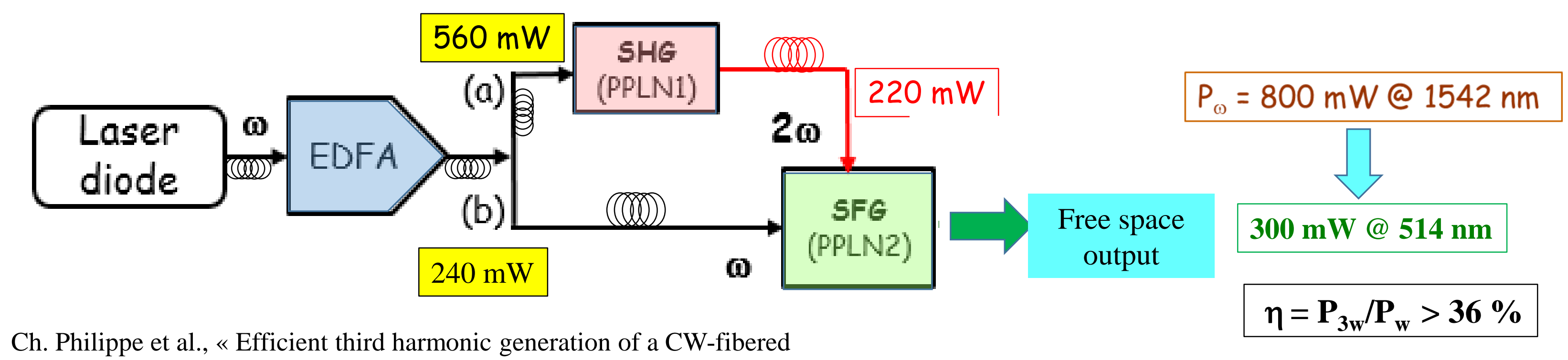

$1.5 \mu \mathrm{m}$ laser diode”, Appl. Phys. B 122 (10) 265 (2016)

Only $10 \mathrm{~mW}$ needed for iodine spectroscopy

Frequency modulation applied on the green beam 
Frequency Tripling Process: Two distinct setups have been developed

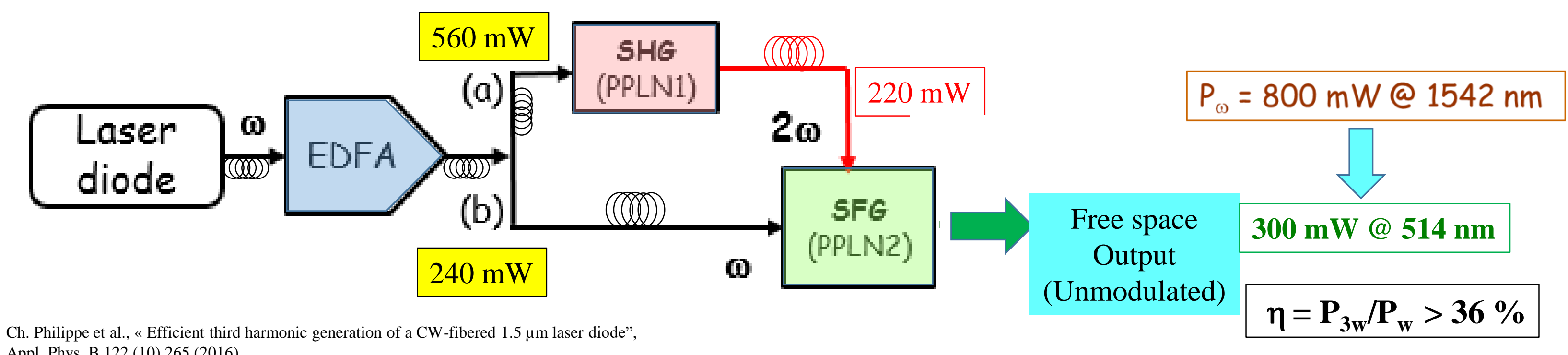

Ch. Philippe et al., «Efficient third harmonic generation of a CW-fibered $1.5 \mu \mathrm{m}$ laser diode", Appl. Phys. B 122 (10) 265 (2016)

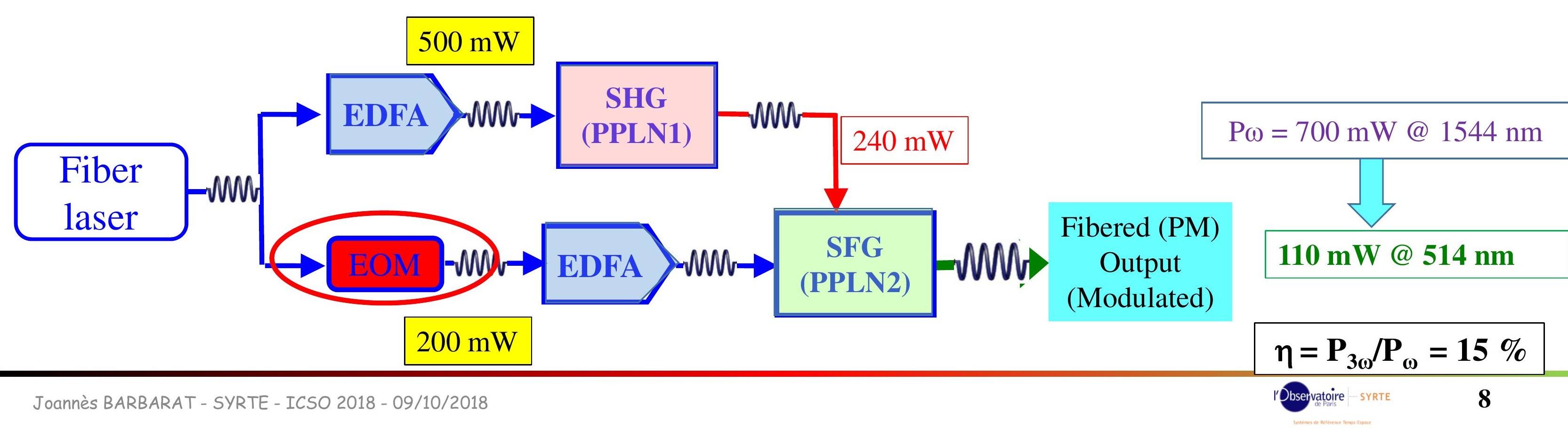




\section{Iodine Doppler free spectroscopy}

\section{A: Modulation transfer spectroscopy (MTS) (1/2)}

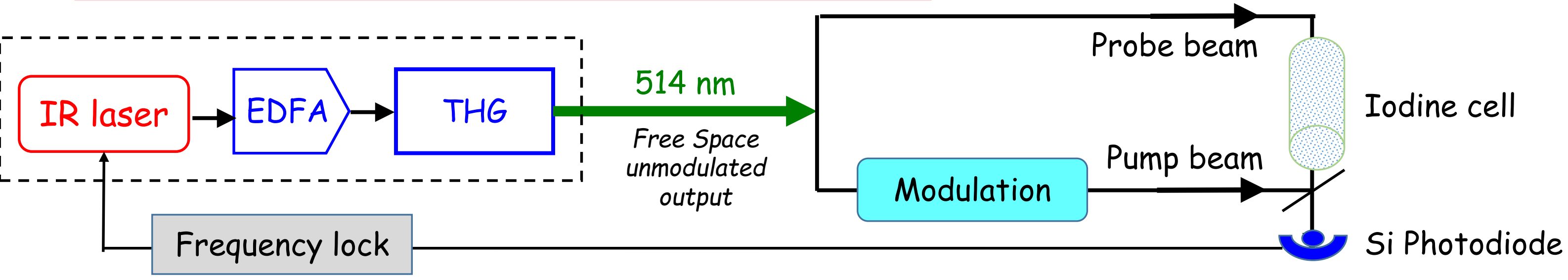

Free space output radiation at $514 \mathrm{~nm}$, from the THG process.

Use of the MTS technique $\longrightarrow$ The output beam is split in two parts : Pump \& Probe beams.

Modulation applied on the pump beam.

First derivative of the iodine saturation signal is used.

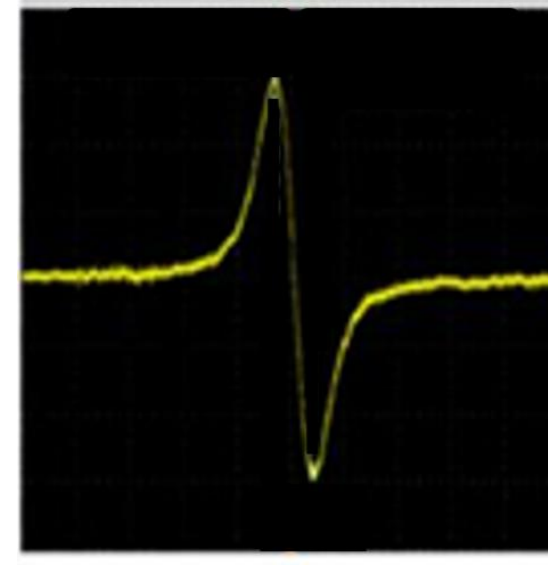




\section{Iodine Doppler free spectroscopy}

\section{B: Frequency modulation technique}

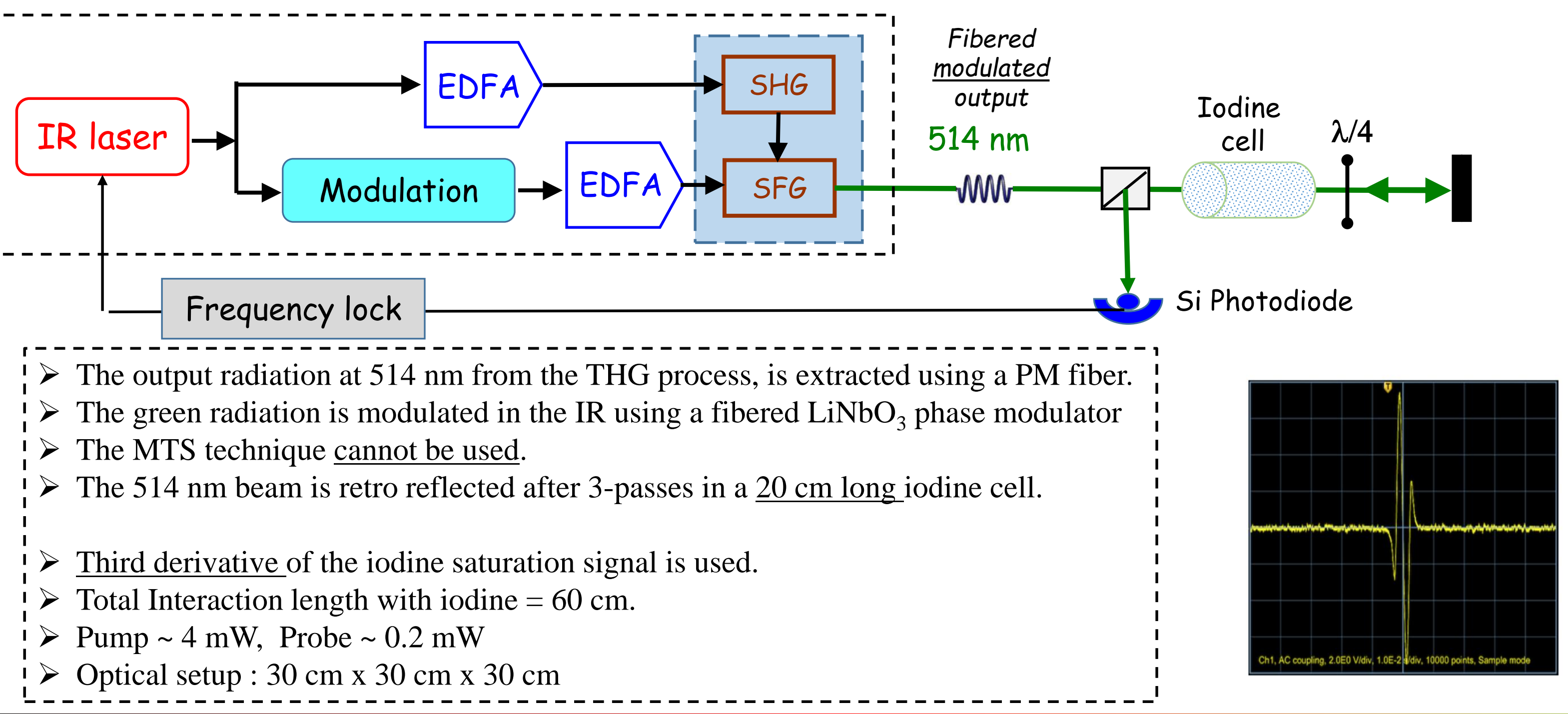




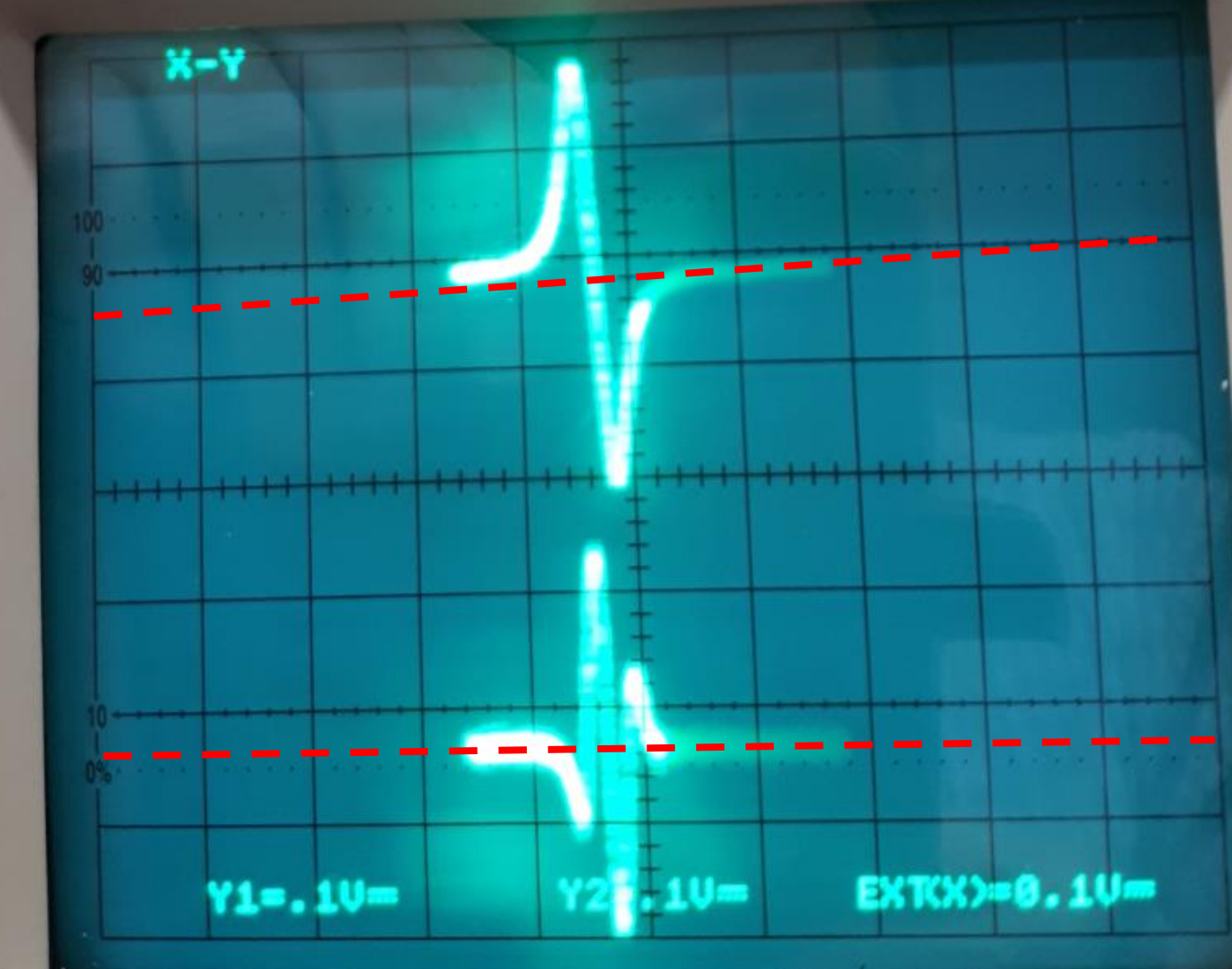

$1^{\text {st }} \& 3^{\text {rd }}$ derivative of the $a_{1}$ hyperfine component of the $\mathrm{P}$ (46) [44-0] iodine line at $\sim 514.5 \mathrm{~nm}$ 


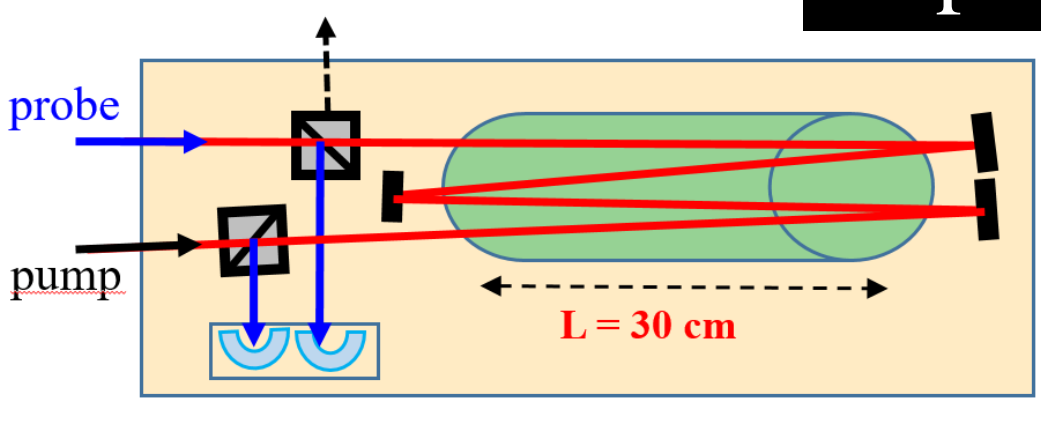

Cell:

$\mathrm{L}=\mathbf{3 0} \mathrm{cm}$

$\Phi=30 \mathrm{~mm}$

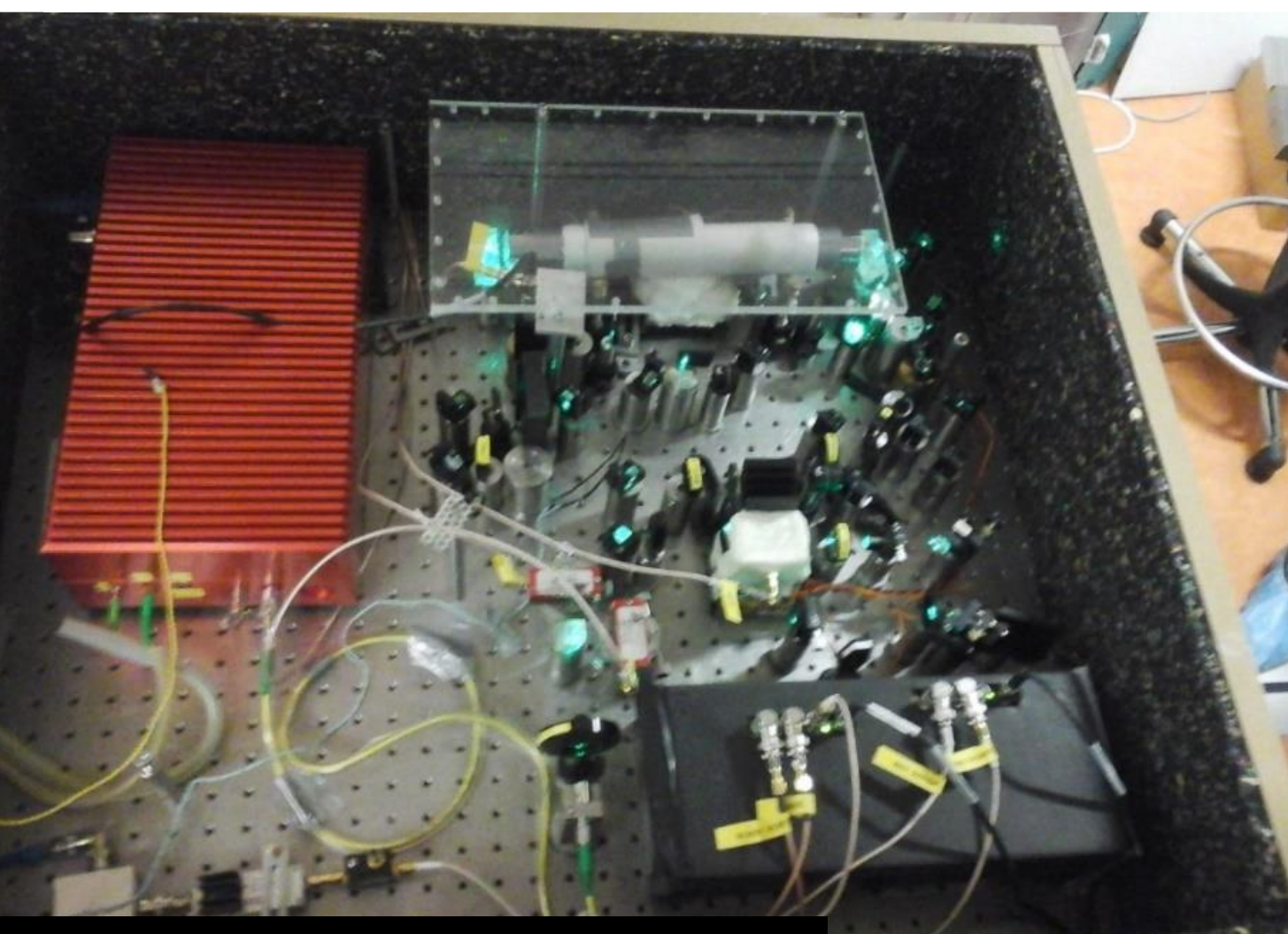

$80 \times 80 \times 20 \mathrm{~cm}^{3}=\underline{\mathbf{1 2 8}}$ litres

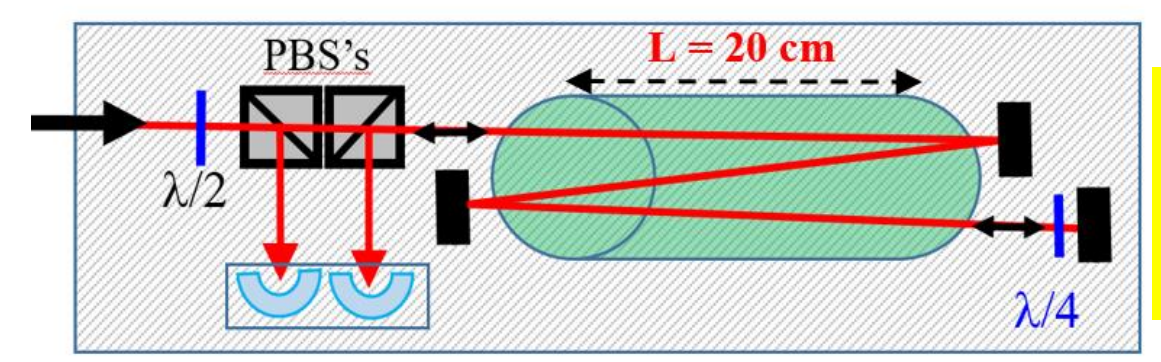

Cell:

$\mathrm{L}=20 \mathrm{~cm}$

$\Phi=18 \mathrm{~mm}$

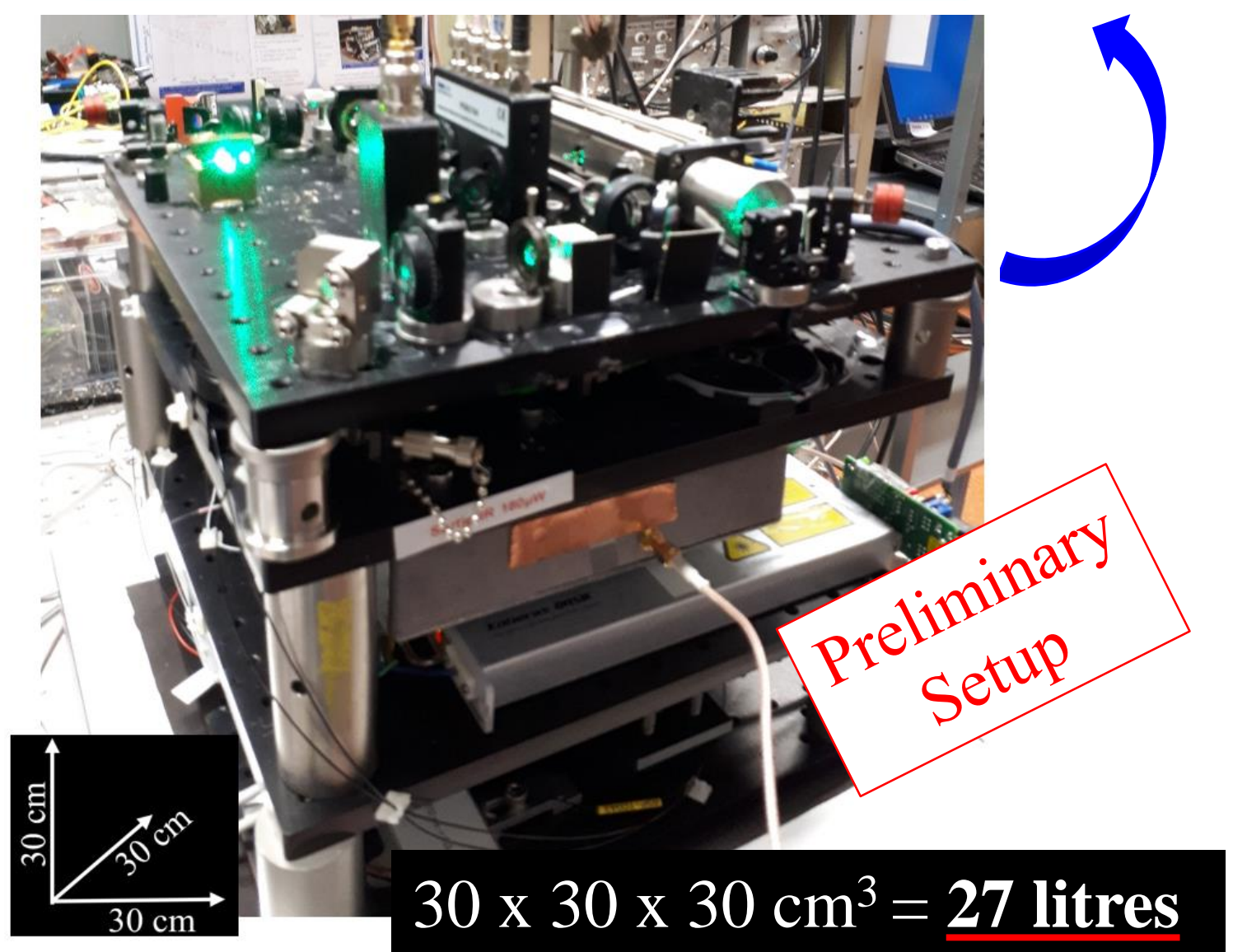




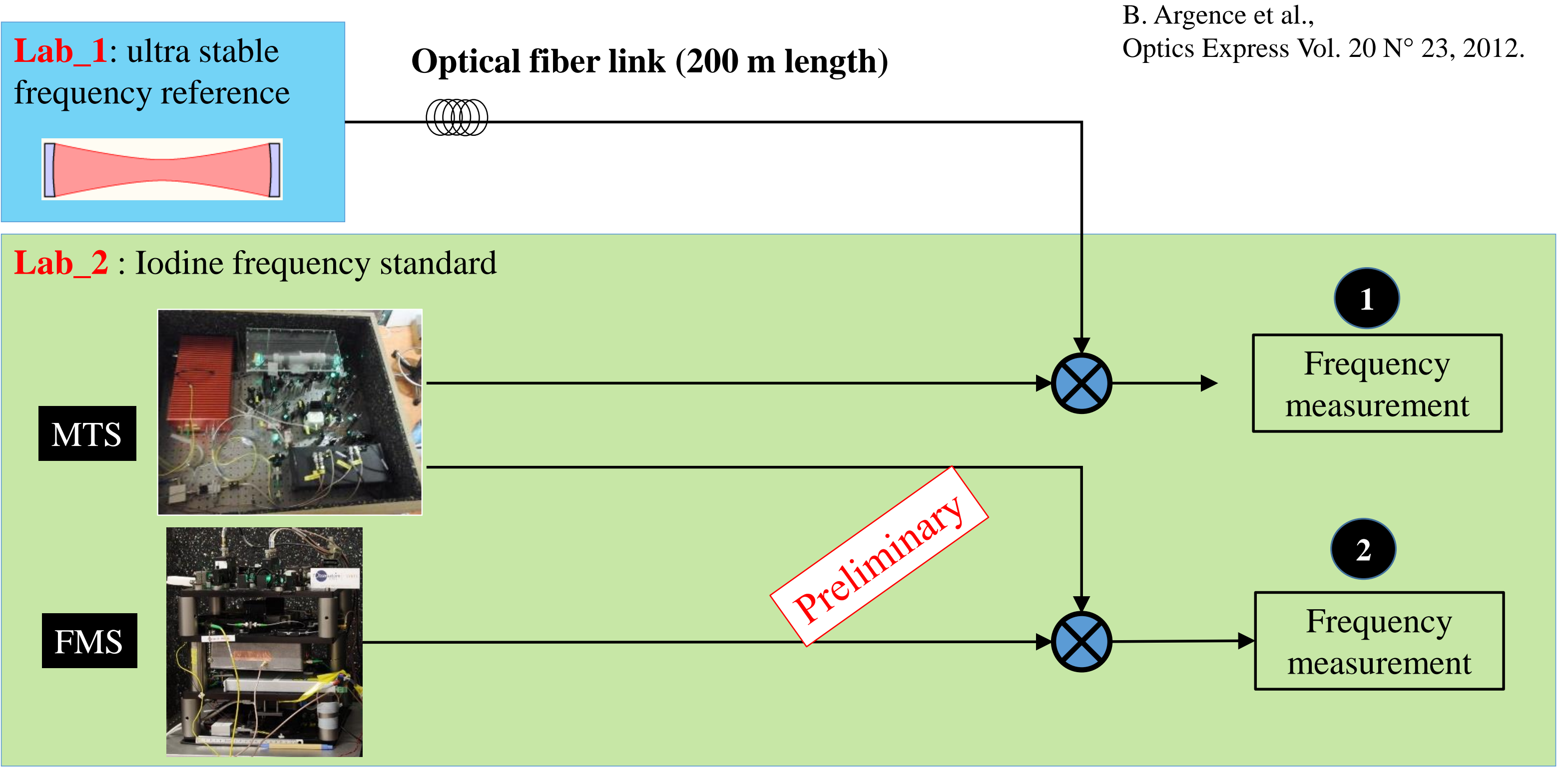


$>$ Modulation transfer spectroscopy

$>\quad$ With Optical power stabilization

$>$ Using cooled iodine cell $\left(-11^{\circ} \mathrm{C}\right)$

$>$ Interaction length $=\underline{\mathbf{1 2 0} \mathbf{c m}}$

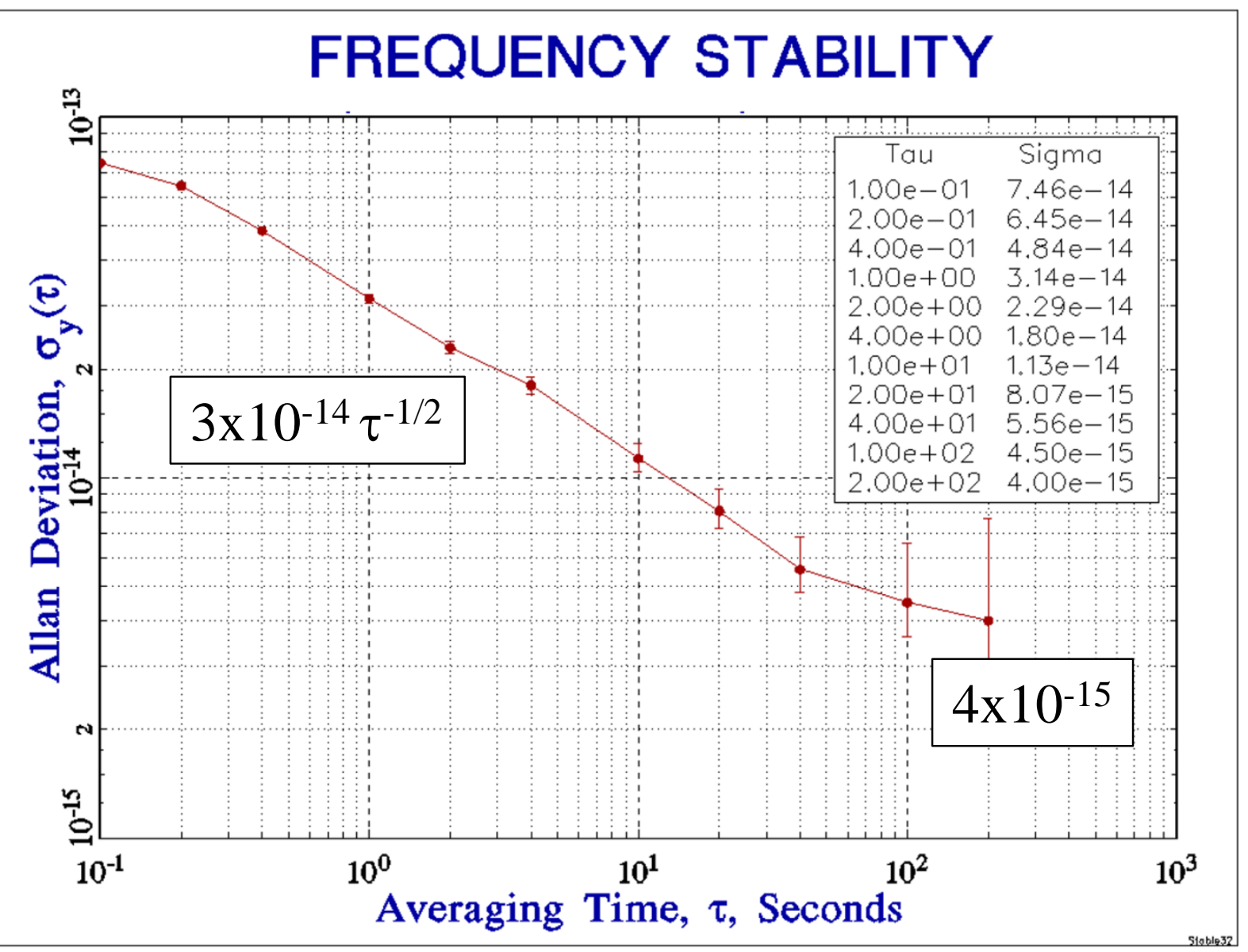

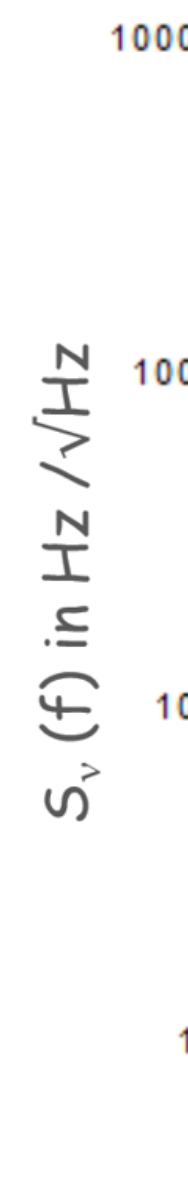

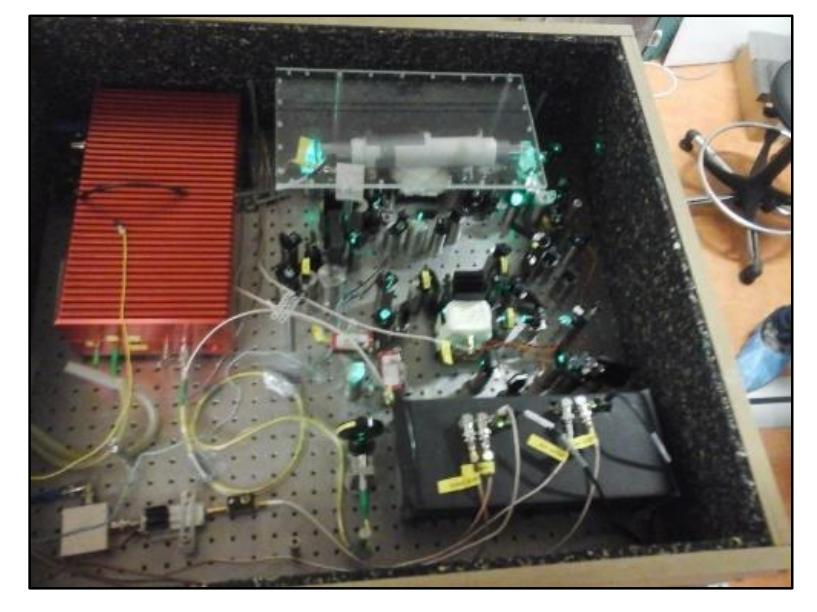


Frequency Modulation Spectroscopy

$>$ Using Uncooled iodine cell $\left(+20^{\circ} \mathrm{C}\right)$

$>$ Interaction length $=\underline{\mathbf{6 0} \mathbf{~ c m}}$

$>$ Without Optical power stabilization
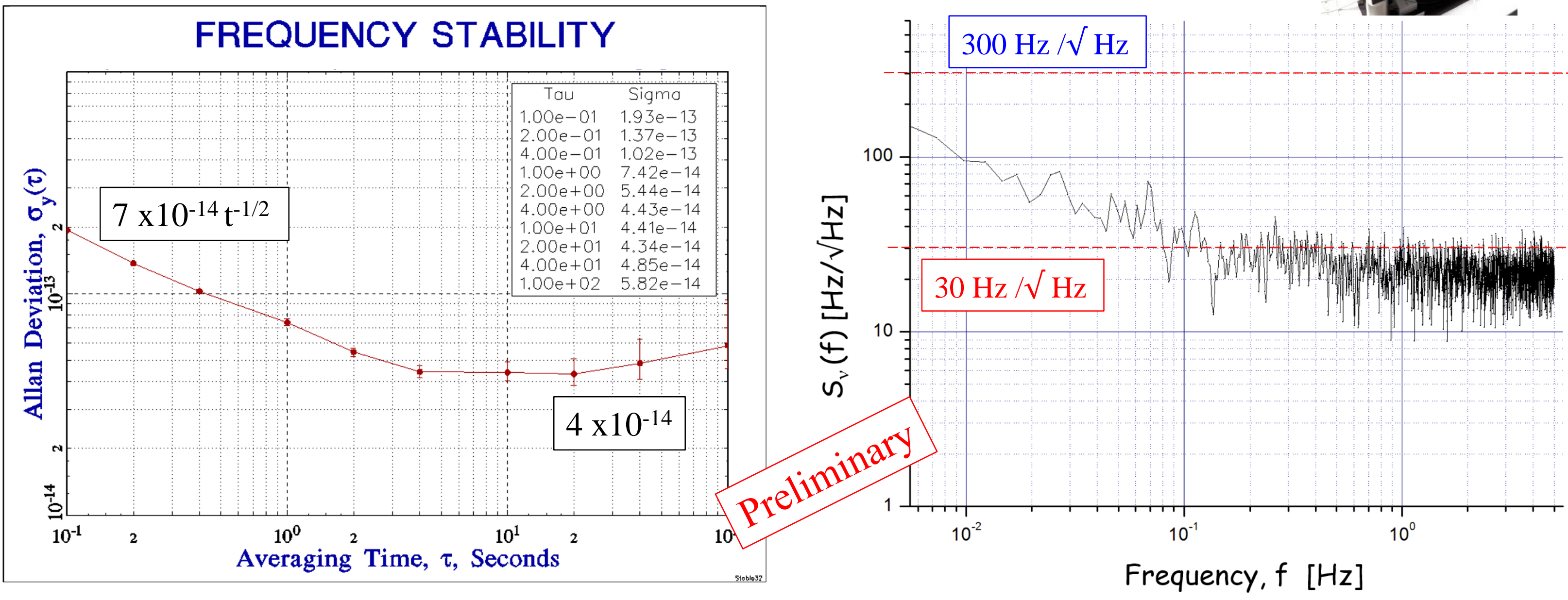
$\square$ Efficient frequency tripling process of a Telecom laser diode $(\sim 1.54 \mu \mathrm{m})$ is demonstrated

$>$ A fully fibered optical architecture is used.

$>$ Harmonic power at $514 \mathrm{~nm}: \mathrm{P}_{3 \omega}>100 \mathrm{~mW}$ is obtained.

$>$ Total electrical consumption $<20 \mathrm{~W}$ is used.

$>$ Less than $10 \mathrm{~mW}$ at $3 \omega$ is needed for the frequency stabilization purpose.

$\square$ Frequency stabilization in the $10^{-14}$ range is already demonstrated for our fibered compact setup, using a short sealed iodine cell.

$>$ A residual frequency noise below $30 \mathrm{~Hz} / \sqrt{\mathrm{Hz}}$ is demonstrated, by comparing to an independent frequency reference.

$>$ The preliminary fibered optical setup occupies a total volume $\sim 27$ litres. 
$\checkmark$ Development of a fibered-compact Iodine stabilized laser system (volume $\sim 10$ litres). $\checkmark$ Development of a "fibered iodine cell" (on going)*.

$\checkmark$ Residual frequency noise $<10 \mathrm{~Hz} / \sqrt{\mathrm{Hz}}$ (As already demonstrated at $1542 \mathrm{~nm} / 514 \mathrm{~nm}$ )

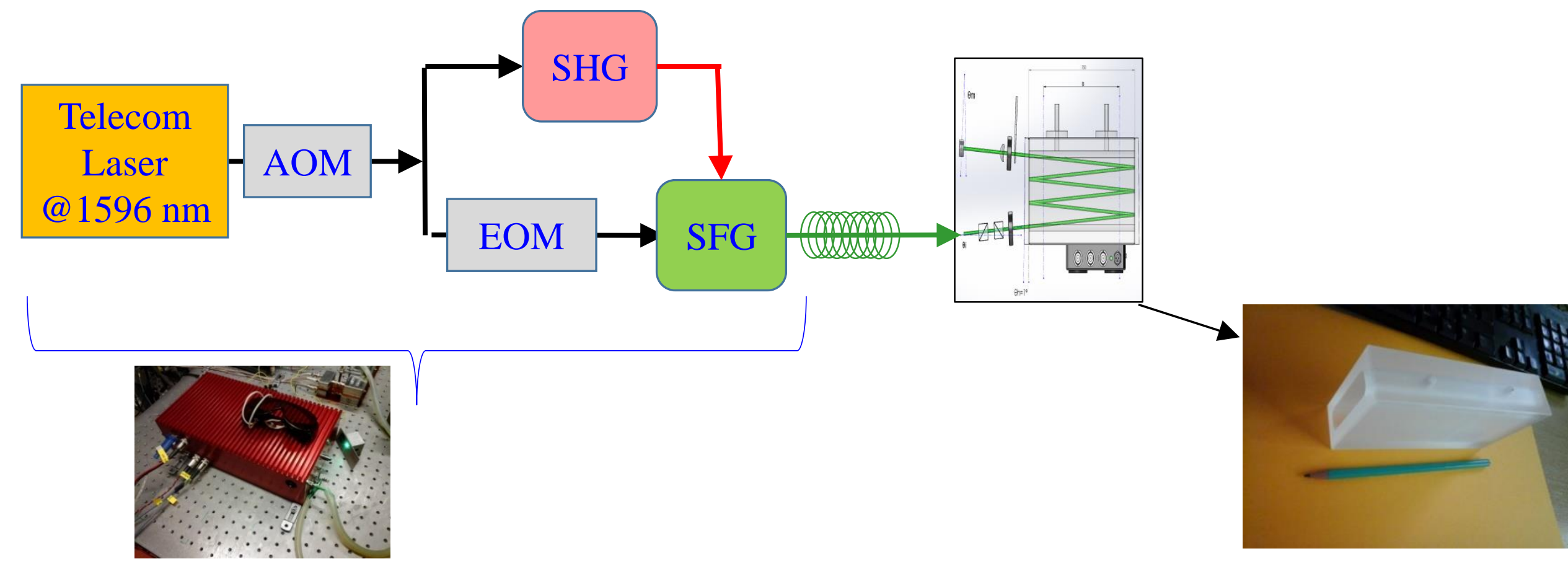

Volume $\sim 5$ litres

(demonstrated at $1542 \mathrm{~nm}$ )
* Under development in collaboration with SODERN \& ISI (Brno, CZ) 


\section{Future development}

$\checkmark$ New optical frequency standard is planned at $1596 \mathrm{~nm}$ $\checkmark$ Use as an ultra-stable frequency reference for phase-locking a $1064 \mathrm{~nm}$ laser $\checkmark$ Tripled $1596 \mathrm{~nm}$ fiber laser $=$ SHG of a Nd:YAG laser $\checkmark$ Such laser is widely involved in various space missions

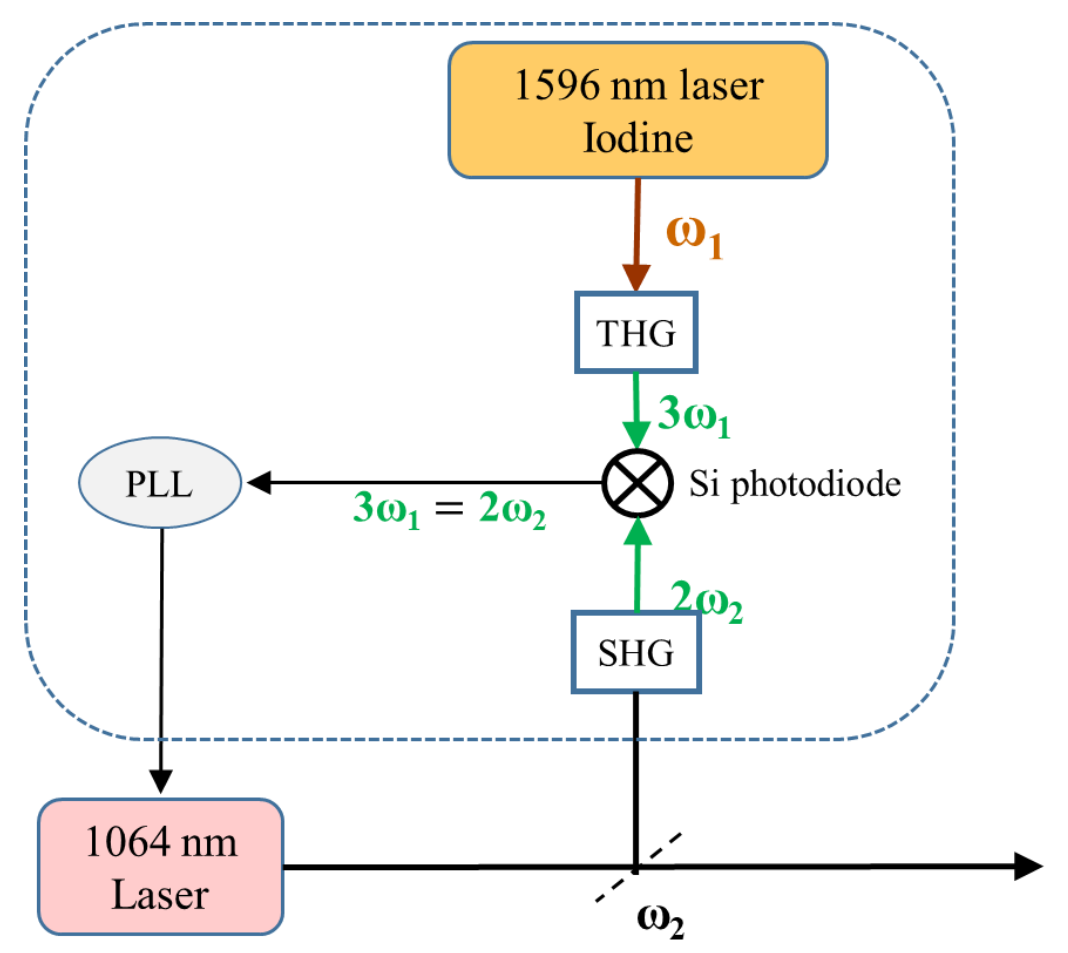


$>$ This work is supported by :

* The French space agency (CNES) Contract :R-S17/SU-0001

* Labex FIRST-TF

* PN-GRAM (CNES,CNRS)

$>$ The PhD thesis of is supported by FIRST-TF and SYRTE 


\section{Other applications}

Ultra-stable frequency reference for optical links (Inter-satellites / ground to space) Accurate laser ranging

Up-Down optical communications

$>$ Navigation, ....

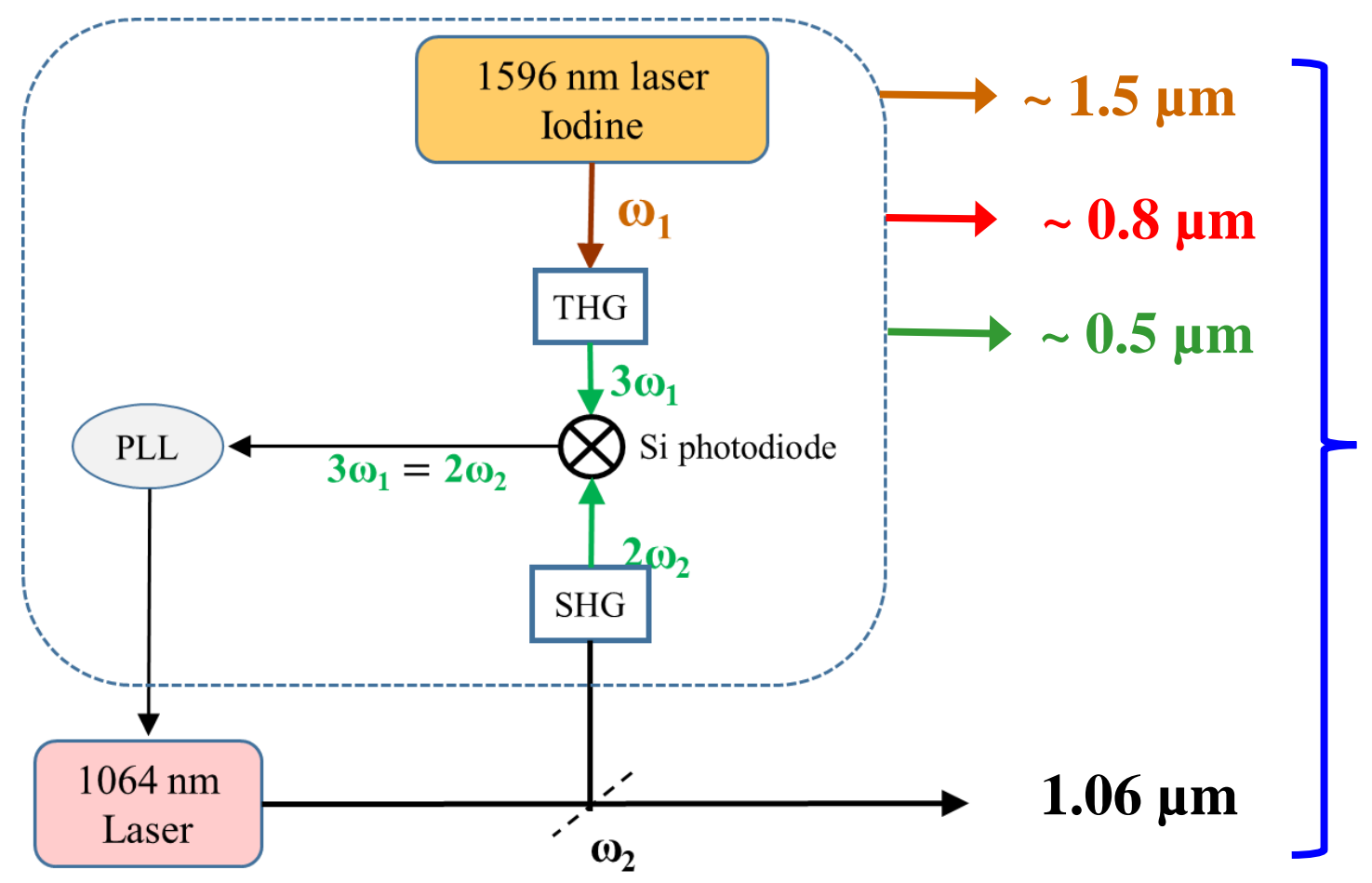

Up to 4-Phase Coheres Optical radiations

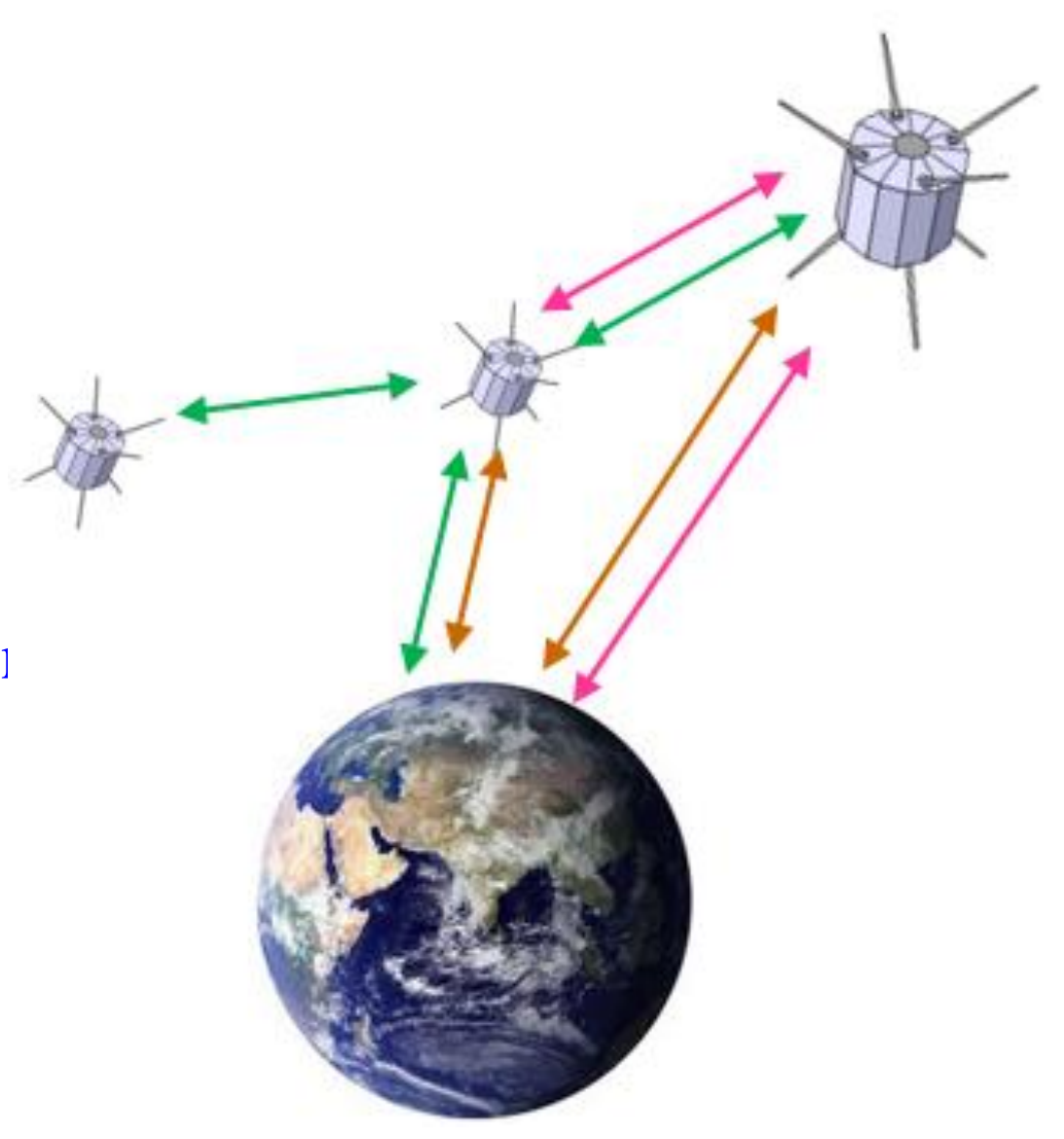




\section{FREQUENCY STABILITY}

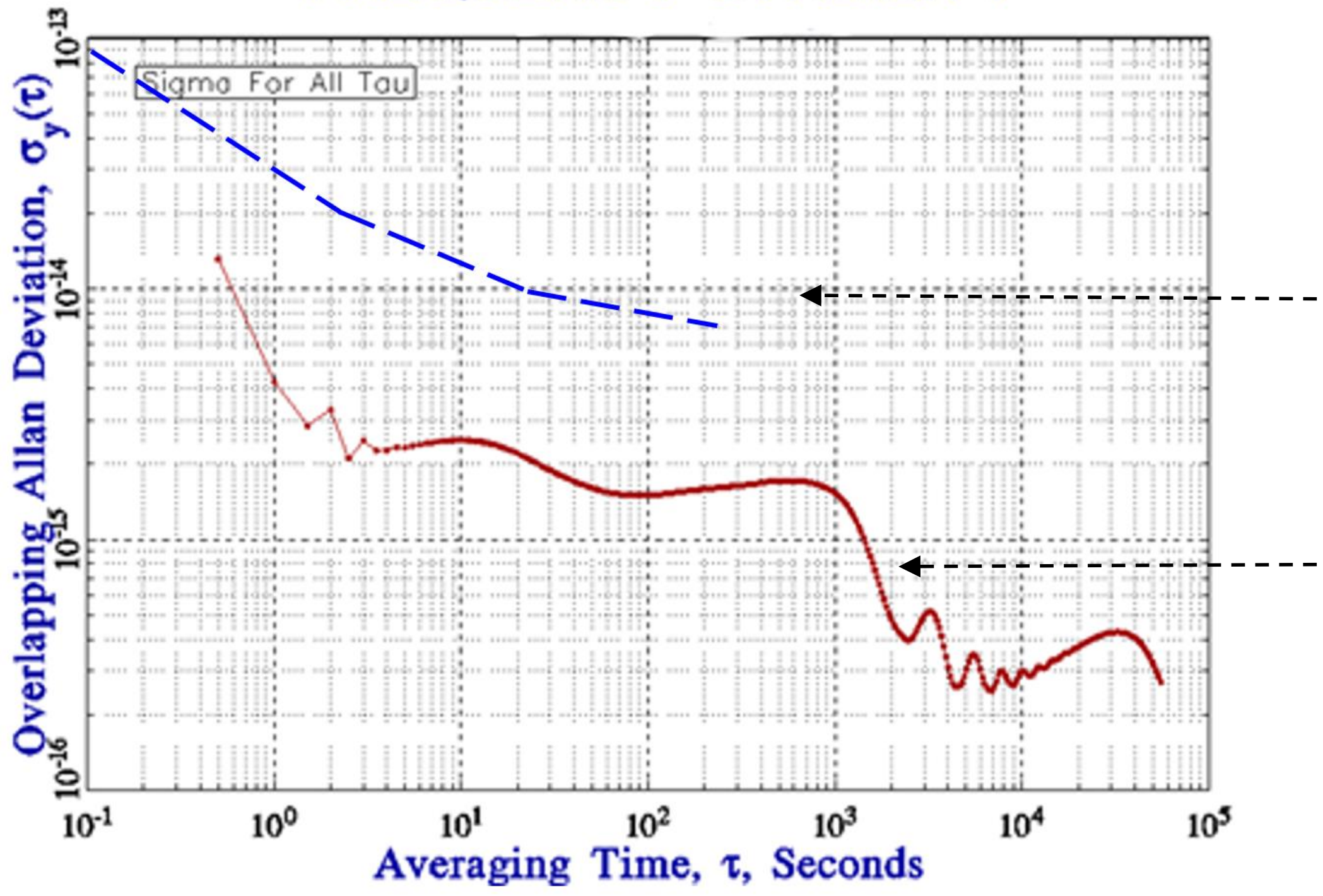

Typical Iodine frequency stabilized laser stability

Measured frequency noise associated to the uncompensated optical fiber link ( $200 \mathrm{~m}$ long $)$ 
Hyperfine iodine center line sensitivity to a weak external magnetic field

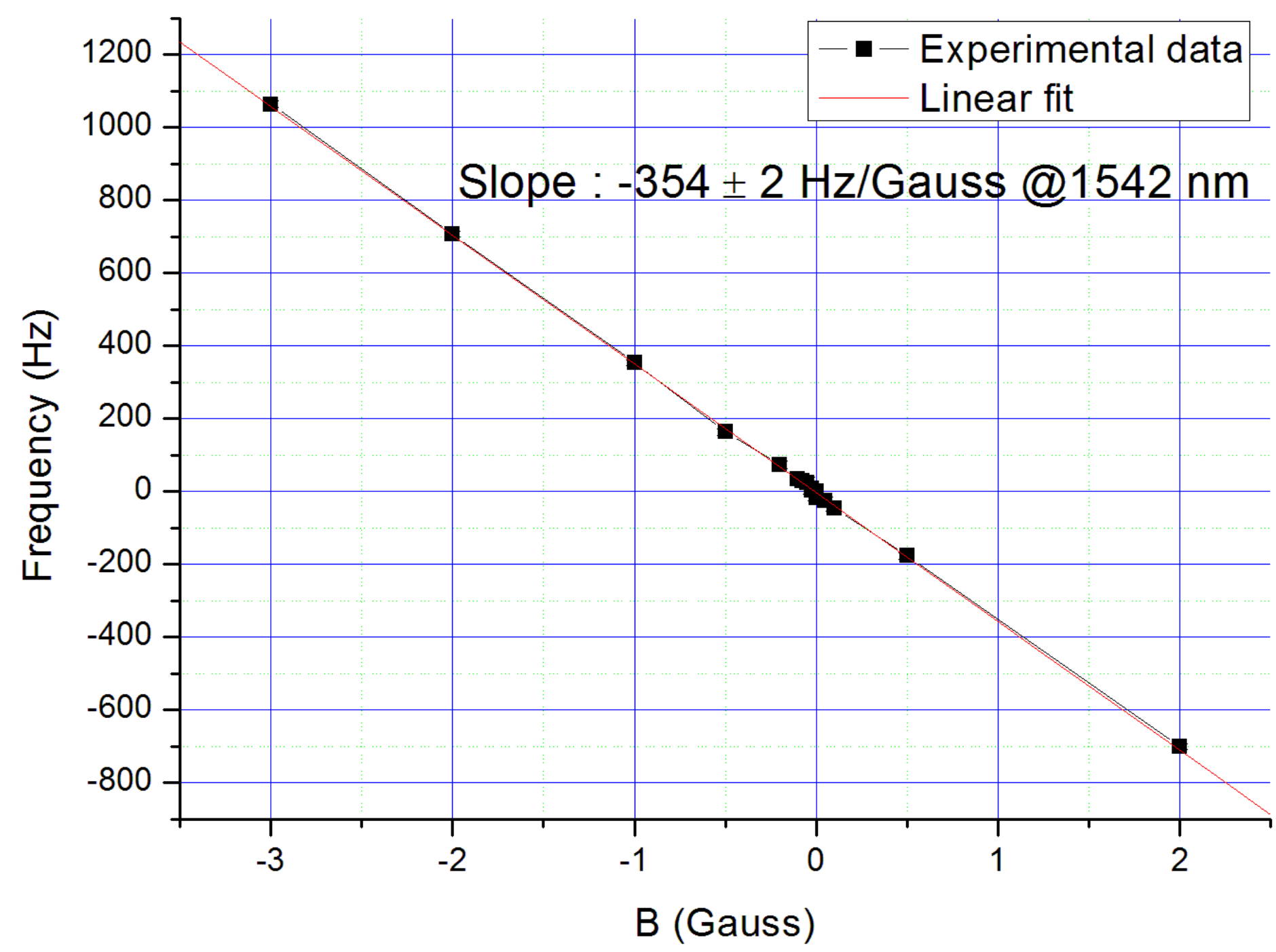

\section{Linear frequency shift : \\ $\sim 1.81^{-15} /$ mGauss}

(measurement for the $\mathrm{a}_{1}$ hyperfine component of the R 34 (44-0)

${ }^{127} \mathrm{I}_{2}$ line at $\sim 514.017 \mathrm{~nm}$ ) 


\section{Frequency Tripling Process: Fully fibered optical setup}

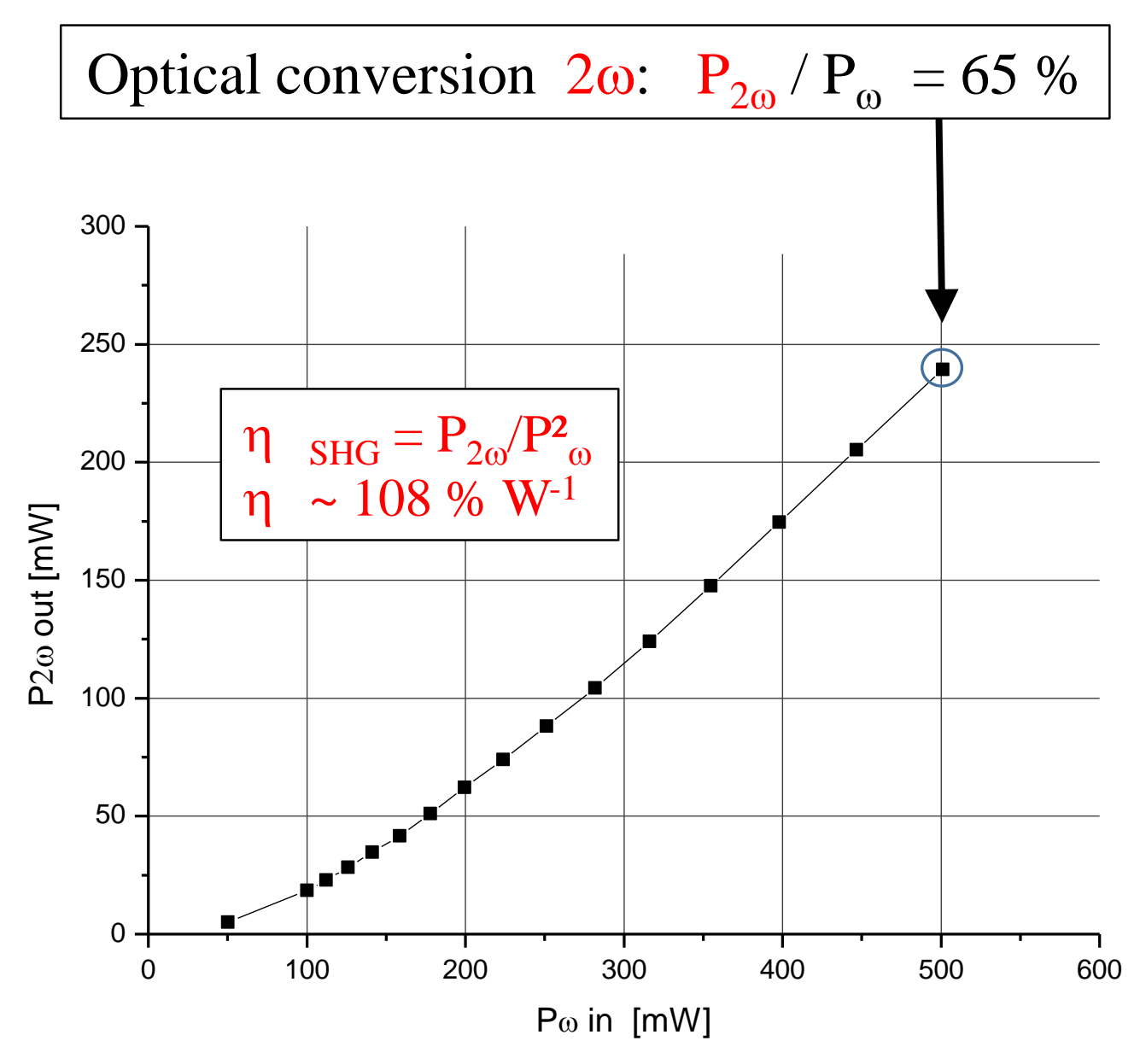

SHG

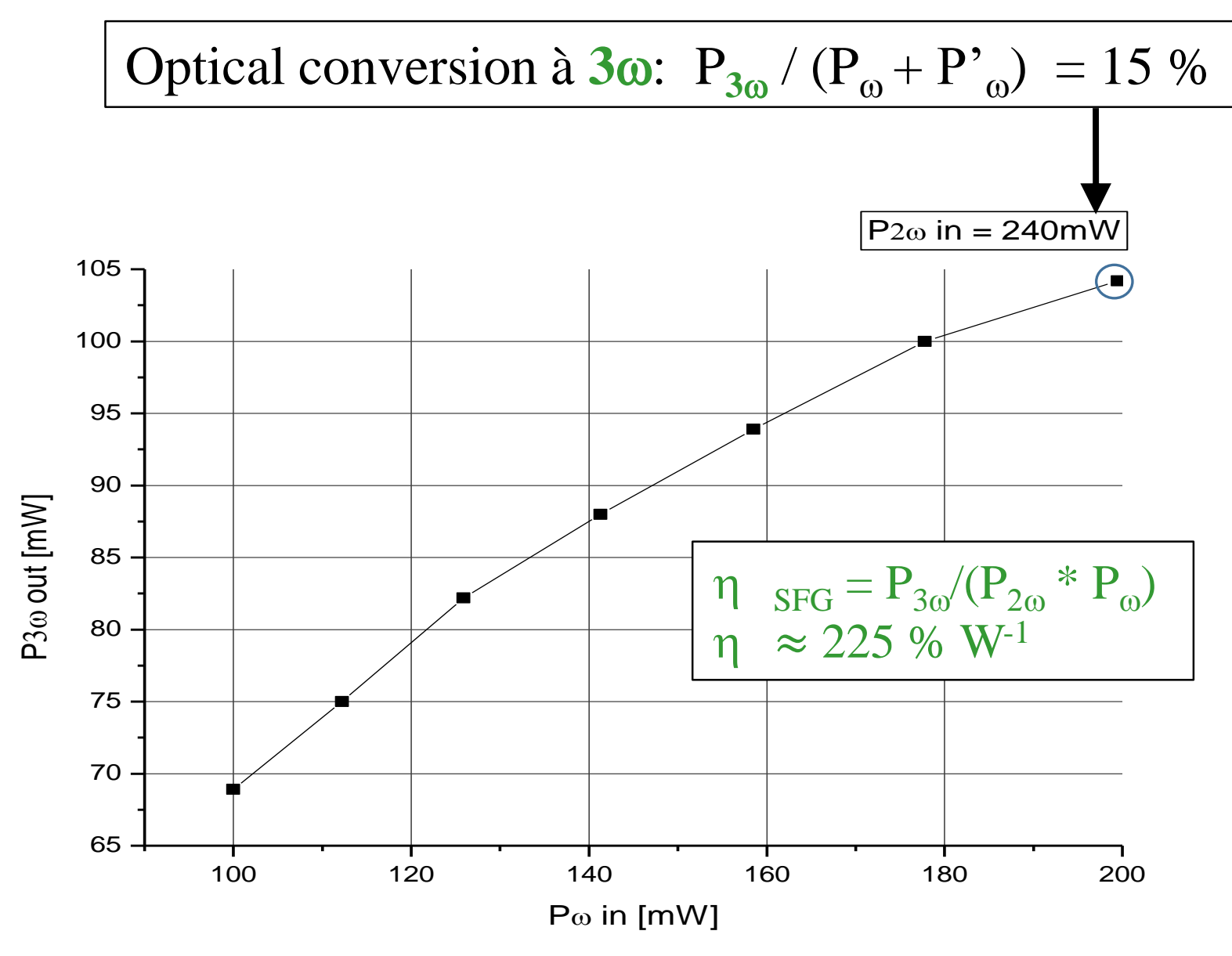

SFG 